\title{
Sustainability and wellbeing: the dynamic relationship between subjective wellbeing and sustainability indicators
}

\author{
Mubashir Qasim, ${ }^{1}$ and Arthur Grimes ${ }^{2,3 *}$ (D) \\ ${ }^{1}$ School of Accounting, Finance and Economics, University of Waikato, Hamilton, New Zealand; ${ }^{2}$ Motu \\ Economic and Public Policy Research, Wellington, New Zealand and ${ }^{3}$ Victoria University of Wellington \\ School of Government, Wellington, New Zealand \\ *Corresponding author. E-mail: arthur.grimes@motu.org.nz
}

(Submitted 31 August 2019; revised 18 August 2020, 6 October 2020; accepted 19 October 2020)

\begin{abstract}
We analyse the relationship between individuals' subjective wellbeing (SWB) and measures of their country's sustainability. SWB data are sourced from the World Values Survey; sustainability is measured by ecological footprint (EF) and by components of the World Bank's adjusted net savings (ANS) series. ANS, a measure of weak sustainability, represents changes in a country's capital stock including financial, physical, human and natural capital. We show that an increase in strong sustainability, measured by EF and by ANS's natural capital component, is associated with reductions in SWB over the next decade followed by a rebound in SWB over the subsequent decade. We show also that the perfect substitutability assumptions on which ANS is calculated do not hold. Our findings highlight an important political challenge: governments that run sustainable policies may decrease the near-term wellbeing of citizens. This can reduce government's short-term popularity even though the improved sustainability may raise future wellbeing.
\end{abstract}

Keywords: adjusted net savings; ecological footprint; subjective wellbeing; sustainability

JEL classifications: D91; H75; Q01; Q56

\section{Introduction}

The Dasgupta Review (Dasgupta, 2020: 2) states: 'Our economies, livelihoods and wellbeing all rely on Nature.' This emphasis on the criticality of nature for human wellbeing is consistent with a strong sustainability approach that emphasises the importance of protecting natural assets in order to underpin future welfare. By contrast, a weak sustainability approach (Pearce and Atkinson, 1993; Pearce et al., 1996) allows for substitutability between different forms of capital (natural, produced and human) in facilitating future wellbeing outcomes. 
We examine the relationship between different measures of the sustainability of national economic policies and the individual wellbeing of citizens. In doing so, we highlight a difficult trade-off that governments face between running sustainable economic policies and raising the more immediate welfare of their citizens. This trade-off may explain why many governments fail to adopt sustainable economic policies even though doing so may improve the wellbeing of future generations.

We use the World Bank's adjusted net savings (ANS) series - akin to the Genuine Savings (GS) concept adopted by Pearce et al. (1996) - as an indicator to measure weak sustainability. ${ }^{1}$ A positive level of ANS represents an increase in a country's aggregate capital stock defined to include financial capital, produced capital, human capital and some elements of natural capital. A negative level of ANS sees the country running down its (similarly measured) wealth. Researchers have applied ANS as a predictor of aggregate objective wellbeing (e.g., Ferreira et al., 2008). However, far less attention has been given to testing the relationship between ANS and subjective wellbeing at the individual level. Nor has attention been given to testing whether the components of ANS have identical impacts on wellbeing, a result which would be required in order to justify a simple summation of different forms of capital to compile the ANS measure.

The present paper fills these gaps by examining the relationship between ANS (and its components) and future subjective wellbeing (SWB). Natural capital depletion is one of the ANS components; concentration on that component alone would bring us closer to a test of the relationship between strong sustainability and future wellbeing. To investigate this relationship further, we also employ the ecological footprint (EF) measure (see section 2.1) as an alternative indicator of strong sustainability to test its relationship with future wellbeing. While different measures of SWB are available, we use an evaluative definition commonly used in the economics literature, obtained from the World Values Survey question on life satisfaction. ${ }^{2}$ To the best of our knowledge, this study is the first to test whether each of ANS, its components, or EF helps to predict future developments in individuals' life satisfaction relative to prior levels.

Using multiple estimation approaches with unit record data, we find that initial levels for the strong sustainability measures for a country are negatively (and significantly) associated with the future SWB of residents over the next decade. Thus there is a trade-off for policy-makers between running policies that boost short-term wellbeing and adopting policies that meet a strong sustainability test. The relationship between the two turns positive over the following decade. This result is consistent with the hypothesis that running strongly sustainable policies enhances the wellbeing of future generations (Greasley et al., 2014). We do not find such strong results for other components of ANS. Furthermore, we reject perfect substitutability across all components of capital within ANS, raising questions about the suitability of ANS as an aggregate measure of sustainability. We also find that different forms of capital accretion (or depletion) affect different demographic groups, especially according to education and income.

The data source for SWB (the World Values Survey) includes ten countries that have data covering waves 2, 4 and 6 of the survey. These waves are approximately a decade apart, enabling us to analyse decadal changes in wellbeing for individuals in each country. To minimize the risk of omitted variables bias in our estimates, we control for a range

\footnotetext{
${ }^{1}$ ANS is also referred to as comprehensive investment (CI), comprehensive savings (CS) or inclusive wealth (IW). See section 2.1 for references to key papers that analyse ANS, GS, CI, CS or IW.

${ }^{2}$ We use the terms life satisfaction and SWB synonymously. We discuss how life satisfaction relates to other aspects of wellbeing in section 2.2.
} 
of personal variables which have been shown to be associated with individuals' SWB. We also control for a country's initial average level of SWB which is a highly significant predictor of their citizens' future wellbeing; prior studies' omission of this variable has likely resulted in biased estimates of the relationship between sustainability and wellbeing in those studies. All equations also include two macroeconomic control variables to proxy for development status and for short-run macroeconomic disequilibrium.

Sections 2.1, 2.2 and 2.3 of the paper describe EF, ANS and SWB respectively, while section 2.4 reviews the relevant theory linking SWB to sustainability measures. Section 3 details the specifications of our empirical model while section 4 covers the process of collecting and processing data from several sources. In section 5, we present our empirical results using a variety of specifications and estimation methods to test for robustness. In the final section, we draw conclusions with reference to policy challenges highlighted by our results.

\section{Background}

\subsection{Ecological footprint}

EF is a measure of how much area of biologically productive land and water a country requires to produce all the resources it consumes and to absorb the waste it generates. The measure assumes continuation of prevailing technology and resource management practices. Our measure is expressed as hectares per person.

$\mathrm{EF}$ is a measure of resource consumption, and takes a global perspective. Two countries with identical EF values (i.e., with equivalent per capita consumption of resources) may have very different biocapacities. The biocapacity is defined as the capacity of the country's ecosystems to produce biological materials used by people and to absorb their waste material. The measure is again based on existing management schemes and extraction technologies. Two countries with similar levels of EF may have very different ecological deficits where this deficit represents the difference between a country's EF and its biocapacity. For instance, in our sample of countries, Argentina had an EF of 3.1 in 1990 which is well below its estimated biocapacity of 6.8. By contrast, South Africa had a similar EF at 3.4, but this was well above its biocapacity of 1.5. The EF approach does not include forms of capital beyond the ecosystem in its calculation of ecological deficit. Thus it is positioned clearly as a measure of strong sustainability.

\subsection{Adjusted net savings}

ANS is an indicator of sustainable development at the macro-level over the long-run. ${ }^{3}$ ANS was first introduced by Pearce and Atkinson (1993) as an indicator of 'weak sustainability' based on the reformation of the Hartwick Rule (Hartwick, 1977, 1990). According to the Hartwick Rule, income from the exploitation of non-renewable resources should be reinvested in renewable resources in order to maintain total wealth and to achieve non-declining wellbeing over time. This rule emerged from the Hicksian definition of income as being the maximum amount of consumption in one period that does not

\footnotetext{
${ }^{3}$ For additional information, see Dasgupta and Heal (1974), Solow (1974), Pearce and Atkinson (1993), Hamilton and Clemens (1999), Ferreira and Vincent (2005), Dietz and Neumayer (2007), Ferreira et al. (2008), Gnègnè (2009), Arrow et al. (2012), Blum et al. (2013), Hanley et al. (2015), Hanley et al. (2016), Blum et al. (2017), Greasley et al. (2017), Greasley and Madsen (2017) and Qasim et al. (2020).
} 
compromise the ability to afford the same level of consumption in the following period (Hicks, 1946).

The concept of weak sustainability is rooted in the argument that natural, human, financial and produced capital are substitutable. This concept emerged in the 1970s when neoclassical models of economic growth were extended to account for non-renewable natural capital as a factor of production. By contrast, 'strong sustainability' views natural capital as being largely non-substitutable for the generation of wellbeing (e.g., Georgescu-Roegen, 1971). Sneddon et al. (2006) characterise debates between advocates of weak versus strong sustainability as in essence being debates over the substitutability of ecosystem-derived resources. By splitting ANS into its components, we test whether the perfect substitutability assumption that underlies the weak sustainability approach holds.

A weakly sustainable economy is defined as one which saves more than the combined depreciation of its stocks of capital (Pearce and Atkinson, 1993). When ANS takes negative values, it indicates that the country's wealth is being reduced, resulting in an unsustainable development path. Sustainability, under this approach, involves maintaining total wealth, defined as the sum of human capital, produced capital and natural capital (Dasgupta and Mäler, 2000; Hamilton and Atkinson, 2006).

ANS is calculated by the World Bank as net national savings plus education expenditure, minus energy depletion, mineral depletion, net forest depletion, and carbon dioxide and particulate matter (PM) emissions damage. ${ }^{4}$ The World Bank publishes ANS estimates for all countries with data starting - where available - in 1970. A description of the components of ANS and how it is calculated is provided in the online appendix.

\subsection{Measuring wellbeing}

Wellbeing results from a set of factors that are required for a flourishing life, and has been measured in a variety of ways. Some approaches are country-specific (e.g., McGregor et al., 2007) while others are formulated so that measurements are consistent across countries. We require consistent cross-country data so we focus on this latter set of measures. Some cross-country measures compile and/or amalgamate a number of objective and subjective factors that may be related to wellbeing. This methodology in part reflects the influence of Sen's capabilities approach (Sen, 1999) that emphasises the capability to achieve a range of functionings rather than emphasising the outcomes themselves (see also McGregor et al., 2007; Cummins, 2012; MacKerron, 2012).

Delhey and Kroll (2013) discuss a range of well-known cross-country indices of wellbeing that incorporate multiple domains (such as health, education, income, housing, etc.). These indices include: the UNDP's Human Development Index (HDI) and Inequality-adjusted Human Development Index (I-HDI), the OECD's Better Life Index (BLI), the Weighted Index of Social Progress (WISP), the Wellbeing Index (WBI), and the Social Development Index (SDI). They compare how closely these indices are correlated with average SWB of each country which they treat as an encompassing indicator of a country's wellbeing. Correlations of the wellbeing indices with average SWB range from 0.35 to 0.56 (all significant at the 5 per cent level). Thus Delhey and Kroll conclude that SWB can be regarded as an overarching measure that encompasses insights yielded by a range of composite wellbeing indicators. Furthermore, SWB has an advantage as

\footnotetext{
${ }^{4}$ The World Bank also publishes a measure of ANS that excludes particulate matter emissions damage; we adopt the fuller (inclusive) measure.
} 
a measure of wellbeing relative to the index number approaches in that it measures residents' own perceptions of how satisfactory their life is, rather than being subject to weights imposed by an external party.

Given this evidence, our study focuses on evaluative SWB as an indicator of a country's wellbeing. We adopt this approach also since SWB is conceptually related to the standard maximand used in economics, i.e., individual utility (MacKerron, 2012).

There are multiple measures of evaluative SWB available (Veenhoven, 2007). Delhey and Kroll (2013) analyse the relationship between three commonly-used measures of SWB across a broad range of countries: (i) the Cantril ladder of life (Cantril, 1965), in which respondents define their life situation relative to the best and worst life that they can imagine; ${ }^{5}$ (ii) a measure of overall life satisfaction which asks people to rate their lives on a 0 to 10 or on a 1 to 10 scale $^{6}$ and (iii) a measure of current (or momentary) happiness. ${ }^{7}$ Other surveys, including the Gallup Poll, survey respondents' positive affect (happy emotions) and negative affect (unhappy emotions). For OECD countries, Delhey and Kroll report cross-country correlations of: 0.77 between the Cantril ladder and WVS measures of life satisfaction; 0.81 between the WVS measures of life satisfaction and happiness; and 0.69 between the Cantril ladder and WVS happiness. OECD (2011) reports a cross-country correlation coefficient of 0.47 between the Cantril ladder and the 'affect balance' (positive affect minus negative affect, from the Gallup Poll). The various measures are therefore strongly positively correlated, and studies report similar results using both a measure of life satisfaction and a measure of happiness where each is used alternatively as an independent variable in a regression (e.g., Polgreen and Simpson, 2011). ${ }^{8}$

Of the various SWB measures available, the life satisfaction measures are found to be more stable across time for individuals than are happiness (or affect) measures which survey more fleeting emotional states (Diener et al., 2010; Helliwell et al., 2012) and they tend also to be more closely related to standard economic variables such as income or wealth (see Dodds, 1997; Frey and Stutzer, 2002; Helliwell, 2003; Cummins, 2012). Several international repeat surveys of SWB exist, including the Gallup Poll, Eurobarometer Surveys, European Values Surveys (EVS), General Social Surveys (GSS), and World Values Surveys (WVS). We use the last of these surveys owing to its timespan.

While wellbeing may, in part, be socially and culturally determined (Heine et al., 1999), research shows a considerable degree of consensus about key determinants of wellbeing across survey locations. Important personal characteristics include age, sex, cultural and religious affiliations, welfare of relatives and friends, strengths of social network, and marital status (see Gross et al., 1997; Diener et al., 1999; Frey and Stutzer, 2002; Helliwell and Putnam, 2004; Kahneman and Krueger, 2006; Helliwell et al., 2012). At a macro level, nations with higher wellbeing tend to score higher on human rights, equality, justice, and democratic governance.

\footnotetext{
${ }^{5}$ The Cantril ladder question is used in the Gallup Poll.

${ }^{6}$ This type of question is included in several countries' General Social Survey and in some international surveys including the World Values Survey (WVS); see: http://www.worldvaluessurvey.org/wvs.jsp.

${ }^{7}$ This type of question is also included in the WVS.

${ }^{8}$ Another form of SWB that is surveyed across countries is 'purpose in life' or eudemonia. This is a somewhat different concept from evaluative wellbeing, and intuitively is less likely to be related to issues of sustainability so is not considered further here.
} 


\subsection{Relationships between SWB and sustainability}

The contemporaneous relationship between SWB and sustainability indicators, including individual components of ANS such as natural capital, human capital, produced capital and its rate of return (measured by income per capita), has been extensively studied in the literature. Studies that focus just on the natural capital component can be regarded as tests of strong sustainability, while those that include all components test for weak sustainability. The predictive power of sustainability measures to explain changes in national level wellbeing - but not individual level wellbeing - has also been examined (Qasim, 2017). However, many such studies have not adequately controlled for endogeneity or prior levels of wellbeing in a country.

The relationship between SWB and any measure of sustainability (referred to in the following generically as SUS) can be modelled at the individual or country scale, with one or both variables expressed either in levels or changes. At each scale, we can postulate four possible relationships between SWB and SUS: SWB $=f(\mathrm{SUS}), \mathrm{SWB}=f(\Delta \mathrm{SUS})$, $\Delta \mathrm{SWB}=f(\mathrm{SUS}), \Delta \mathrm{SWB}=f(\Delta \mathrm{SUS})$, where $\Delta$ signifies a change in that variable across time. A summary of relevant literature in terms of these specifications is presented in table 1.

Examining table 1, we observe two groups of studies. First, sustainability measures have been used as a predictor of changes in future wellbeing at the national level. For instance, Ferreira et al. (2008) have used GS to predict changes in future real consumption per capita, as a proxy for national level wellbeing.

Second, all prior SWB studies, at both the individual and the aggregate country scale, are formulated using the dependent and the explanatory variables at levels (rather than changes). The use of current variables at levels induces the risk of endogeneity in estimation. To the best of our knowledge, none of the papers has used a sustainability indicator to predict future individual SWB while controlling also for past levels of SWB. The literature on cultural and other determinants of SWB show that it is vital to control for persistent SWB levels across different countries and cultures, so studies that omit this country-specific aspect are likely to be flawed.

\section{Methods}

Consistent with the recommendations of Stiglitz et al. (2010), we focus on individual (rather than aggregate) measures of wellbeing. In terms of the types of models outlined in section 2.4, we focus on specifications in which the change in SWB is a function, ceteris paribus, of the initial level of sustainability of their country (i.e., $\Delta$ SWB $=f($ SUS )). Based on our analysis in section 2, we hypothesize that countries with higher levels of sustainability will perform better, in the long run, in terms of the future change in SWB of their inhabitants. This reflects the increase in resources available to promote the long-run wellbeing of future citizens.

In order to test whether each sustainability measure helps to predict subsequent SWB changes, we control for a set of variables which prior literature shows to have high explanatory power for SWB (Di Tella et al., 2001; Gnègnè, 2009; Grimes et al., 2016; Welsch and Kühling, 2016; Novak and Pahor, 2017). Equation (1) illustrates a baseline model in levels:

$$
\mathrm{SWB}_{i, c, t}=\beta_{0}+\beta_{1} M_{c, t}+\beta_{2} X_{i, t}+\beta_{3} \mathrm{SUS}_{c, t}+\lambda_{w}+\lambda_{c}+\varepsilon_{i, c, t},
$$

where variables are defined as: SWB, subjective wellbeing; $i$, individual; $c$, country; $t$, time; $M$, vector of macro controls; $X$, vector of personal controls; SUS, sustainability 
Table 1 . Key studies including wellbeing and sustainability indicators

\begin{tabular}{|c|c|c|c|c|}
\hline Reference & Dependent variable(s) & Independent ANS-related variable(s) & Type of study LHS vs RHS & Scope of study \\
\hline Novak and Pahor (2017) & SWB & GNI per capita & Levels - Levels & Individual level \\
\hline Greasley et al. (2017) & $\mathrm{PV} \Delta \mathrm{C}$ & $\begin{array}{l}\text { Net national investment, Green investment, } \\
\text { GS, ANS, } \mathrm{Cl} \text { adjusted for minerals, } \mathrm{Cl} \\
\text { adjusted for TFP }\end{array}$ & Changes - Levels & Country level \\
\hline Grimes et al. (2016) & SWB & Fiscal variables & Levels - Levels $^{a}$ & Individual level \\
\hline Hanley et al. (2016) & $\mathrm{PV} \Delta \mathrm{C}$ & GS, GS adjusted for TFP & Changes - Levels & Country level \\
\hline Greasley et al. (2014) & $\mathrm{PV} \Delta \mathrm{C}, \mathrm{PV} \Delta \mathrm{W}$ & GS and its individual components & Changes - Levels & Country level \\
\hline Blum et al. (2013) & $\mathrm{PV} \Delta \mathrm{C}$ & GS and its individual components & Changes - Levels & Country level \\
\hline Engelbrecht (2012) & SWB & $\begin{array}{l}\text { Total wealth per capita, GNI per capita, } \\
\text { natural capital per capita, produced } \\
\text { capital, intangible capital }\end{array}$ & Levels - Levels & Country level \\
\hline Verme (2011) & SWB & income, country's wealth & Levels - Levels & Individual level \\
\hline Pittau et al. (2010) & SWB & personal income, national income & Levels - Levels & Country level \\
\hline Engelbrecht (2009) & LS, Happiness, SWB Index & Natural capital per capita, GNI per capita & Levels - Levels & Country level \\
\hline Gnégné (2009) & $\Delta \mathrm{HDI}, \Delta \mathrm{IMR}$ & $\begin{array}{l}\text { ANS per capita, NNS per capita, ANS_E, } \\
\text { ANS_P, ANS EP, Initial income }\end{array}$ & Changes - Levels & Country level \\
\hline Bonini (2008) & LS & HDI, ESI, GDP per capita & Levels - Levels & Individual level \\
\hline Ferreira et al. (2008) & $\mathrm{PV} \Delta \mathrm{C}$ & $\begin{array}{l}\text { Gross savings, Net savings, Green savings, } \\
\text { Population adjusted savings }\end{array}$ & Changes - Levels & Country level \\
\hline Vemuri and Costanza (2006) & LS/SWB & HDI, ESP per squared km index & Levels - Levels & Country level \\
\hline Leigh and Wolfers (2006) & SWB, Happiness & HDI, GDP per capita & Levels - Levels & Country level \\
\hline Schyns (2002) & SWB & $\begin{array}{l}\text { income at low medium and high levels, } \\
\text { national income }\end{array}$ & Levels - Levels & Country level \\
\hline
\end{tabular}

SWB: Subjective wellbeing. GS and Cl: Genuine savings and comprehensive investment (alternative terms for ANS). TFP: Total factor productivity. PV $\Delta$ C: Present values (PV) of changes in per capita consumption in real-terms. PV $\Delta \mathrm{W}$ : PV of changes in real wages per capita. PV $\Delta \mathrm{C}$ and PV $\Delta \mathrm{W}$ are used as a proxy for aggregate objective wellbeing. $\Delta \mathrm{HDI}$ : Change in human development index. $\triangle I M R$ : Change in infant mortality rate. ANS_P: ANS calculated without $\mathrm{CO}_{2}$ damage. ANS_E: ANS calculated without education expenditure. ANS_EP: ANS calculated without $\mathrm{CO}_{2}$ damage and education expenditure. ESI: Environmental sustainability index. GNI: Gross national income. NNS: Net national savings. LS: Life satisfaction (SWB) from the WVS. ESP: Ecosystem services product. andividual level study with cross-sectional country fixed effect added. 
indicator; $\lambda_{c}$, country fixed effect; and $\lambda_{w}$, time (wave) fixed effect. The personal controls are: age, sex, income, marital status, employment status and education (all from WVS).

Two macroeconomic control variables proxy for development status and for shortrun macroeconomic disequilibrium. The first macro control variable is life expectancy. We use this variable in preference to real GDP or real GNI per capita since national accounts variables may be poorly measured in developing countries. To give one example, Nigeria (which is included in our dataset) revised its 2013 GDP per capita upwards by 89 per cent (United Nations Economic Commission for Africa, 2014). This revision impacted greatly on its measures of gross and net national savings (and hence ANS), a factor which we discuss further in the data section. Life expectancy has a strong relationship with GDP per capita, a relationship known as the Preston Curve (Preston, 1975; Grimes and Hyland, 2020) and is accurately measured, so is adopted as our preferred indicator of development. The unemployment rate (relative to its long-term average) is used as a measure of short-run disequilibrium.

A problem with this (Levels - Levels) baseline equation is that the model may be subject to an endogeneity problem due to simultaneity (or omitted variables). For example, the current level of sustainability of a country potentially has a strong relationship with its current level of income, and thence its current SWB. For this reason, while equation (1) is our conceptual starting point, we do not adopt it. In equation (2), we mitigate the endogeneity problem by modifying (1) utilising the timing of our variables and adding an extra control variable. We focus our attention on this approach.

$$
\mathrm{SWB}_{i, c, t 1}=\beta_{0}+\beta_{1} M_{c, t 0}+\beta_{2} X_{i, t 1}+\beta_{3} \mathrm{SUS}_{c, t 0}+\beta_{4} \mathrm{SWB}_{c, t 0}+\epsilon_{i, c, t 1} \text {. }
$$

Equation (2) represents a cross-sectional model (and hence excludes country and wave fixed effects $)^{9}$ in which $t 1$ is the 'end-wave' and $t 0$ is the 'initial-wave' for a particular country group. Thus for the first decade analysis, $t 1$ is wave 4 and $t 0$ is wave 2 of the WVS. For the second decade analysis $t 1$ is wave 6 ; wave 2 is retained as $t 0$ since we are testing the relationship of the initial level of sustainability with longer-term outcomes. The personal characteristics are included as at $t 1$ to coincide with the observations of the dependent variable, while the macro variables are included as at $t 0$ (rather than $t 1$ ) for two reasons. First, they adjust for the level of development and/or disequilibrium that may have caused the initial level of sustainability to depart from its expected level in the absence of these factors. Second, if these variables were included as at $t 1$ they would be co-determined with the dependent variable and so would be subject to endogeneity bias. Furthermore, their inclusion as $t 1$ variables would incorporate a potential indirect channel of the effect of sustainability on $\mathrm{SWB}_{i, c, t 1}$ so making it difficult to infer the full effect of the relationship between prior sustainability and wellbeing outcomes. (In the case of the second decade, however, we include $\mathrm{SWB}_{c, t 0}$ from wave 4 so that we can interpret the second decade results as representing the decadal change in SWB.) The model in equation (2) therefore indicates the association between the initial period sustainability indicator and subsequent individual SWB after controlling for personal characteristics, the initial average level of a country's SWB and other macro factors.

Even though we use a long (one to two decade) lag of sustainability in our specifications, we cannot rule out the presence of endogeneity in our estimates (Reed, 2015; Bellemare et al., 2017). Reverse causality is unlikely given the timing of our variables but

\footnotetext{
${ }^{9}$ Inclusion of country fixed effects would result in perfect multicollinearity with the country level variables, while a wave fixed effect is not required as this is not a panel estimate.
} 
omitted variables that are correlated with each of current SWB and the lagged sustainability indicator could be present. This factor is mitigated by our inclusion of $\mathrm{SWB}_{c, t 0}$ which accounts for the effect of time-invariant unobservables on wellbeing; it is a key reason for our inclusion of this variable. Tests of the time series properties of ANS and each of its components indicate each to be stationary variables (albeit with long-lived dynamics) so that any innovation present in the variable at the start of the sample will be considerably diminished over periods of one to two decades, again mitigating any endogeneity concern. ${ }^{10}$ We cannot reject the presence of a unit root for $\mathrm{EF}$, so the results for the ANS natural capital depletion component may be preferable to those using EF when interpreting the results relating to strong sustainability. Even with stationary variables, the presence of time-varying unobservables that are correlated with both wellbeing and the sustainability indicator could still be present. We conjecture that any endogeneity from this source is more likely to be reflected in the estimates for the physical, financial and education sustainability variables, i.e., NNS and education, rather than the natural capital variables, (EF) and (natural capital depletion). The latter are less likely than education or NNS to be affected, for instance, by fiscal and monetary policy decisions that also affect wellbeing.

While SWB is a categorical (ordered) variable, it is common to treat SWB as if it were a cardinal variable and then to estimate using ordinary least squares (OLS). In prior studies this approach has produced similar results (in terms of signs and significance of variables) as ordered logit models (Ferrer-i-Carbonell and Frijters, 2004; Luttmer, 2005) and is easier to interpret. Nevertheless, ordered logit is conceptually a more appropriate estimation method; accordingly, we estimate our models using both OLS and ordered logit (Ologit). As with prior studies, the results from the two approaches are very similar, so we concentrate principally on the OLS estimates. This approach is also consistent with the use of the country mean of SWB as an explanatory variable, which rests on an assumption of cardinality.

Another set of estimation issues arises from the fact that we include country-level data in our regressions for individual wellbeing. This can lead to correlated errors within country observations. One approach to dealing with this issue is to estimate a multilevel model; however the minimum number of countries to include in a multilevel model is normally regarded as at least 30 (Bryan and Jenkins, 2016), making that approach unsuitable given our sample. Instead, recognising the potential for correlated errors, we cluster standard errors by country.

\section{Data}

\subsection{SWB and personal controls}

Self-reported data on SWB and for personal controls ${ }^{11}$ were obtained from the WVS waves 2, 4 and $6 .{ }^{12}$ These waves are approximately a decade apart. Ten countries are included based on their inclusion in all three survey waves. The included countries are: Argentina, Chile, China, India, Mexico, Nigeria, South Africa, South Korea, Spain and

\footnotetext{
${ }^{10}$ Each sustainability variable is tested over their fully available time period for our ten countries using the Levin-Lin-Chu and Im-Persaran-Shin panel unit root tests. Each of ANS and its components rejects a unit root at the 10 per cent level or lower according to both tests.

${ }^{11}$ Online appendix table A1 summarizes data processing across each wave of the WVS data.

${ }^{12}$ For more information, see the World Values Survey site at http://www.worldvaluessurvey.org/ WVSContents.jsp; Wave years: Wave 2: 1990-94; Wave 4: 1999-04; Wave 6: 2010-14.
} 
Table 2. WVS respondent numbers and dates

\begin{tabular}{lccc} 
& \multicolumn{3}{c}{ Number of individuals surveyed } \\
\cline { 2 - 4 } Country & Wave $2(1990-1991)$ & Wave $4(1999-2001)$ & Wave 6 (2010-2013) \\
\hline Argentina & 992 & 1,268 & 1,020 \\
\hline Chile & 1,496 & 1,193 & 988 \\
\hline China & 996 & 991 & 2,252 \\
\hline India & 2,461 & 1,980 & 4,054 \\
\hline Mexico & 1,514 & 1,506 & 2,000 \\
\hline Nigeria & 997 & 2,022 & 1,759 \\
\hline South Africa & 2,696 & 2,995 & 3,521 \\
\hline South Korea & 1,226 & 1,173 & 1,189 \\
\hline Spain & 1,499 & 1,205 & 1,168 \\
\hline Turkey & 1,027 & 3,400 & 1,601 \\
\hline
\end{tabular}

Turkey. The number of individuals surveyed in each wave in each country is shown in table 2 .

The WVS surveys are conducted in each country using stratified multistage random sampling, national random sampling or quota sampling methods. All WVS surveys are conducted in the national language with face-to-face interviews. The SWB question is asked in the local language as:

All things considered, how satisfied are you with your life as a whole these days? Using this card on which 1 means you are 'completely dissatisfied' and 10 means you are 'completely satisfied' where would you put your satisfaction with your life as a whole? (Code one number):

Completely dissatisfied 1, 2, 3, 4, 5, 6, 7, 8, 9, 10 Completely satisfied.

Mean country SWB varies from a low of 6.2 (South Africa) to a high of 7.6 (Chile). In our regression models, age is a continuous variable and both age and age squared are included to capture the curvilinear effect of age on SWB. Sex, marital status, employment status, income level ${ }^{13}$ and education levels are coded as dummy variables; these variables have the following identity prefixes sex_, ms_, es_, in_, and ed_, respectively, in the full results tables (online appendix table A3). Reference groups for these variables are males, employed, lowest income step, and no formal education respectively. We also include dummy variables for missing entries for each variable and a dummy for missing age in our estimates.

\subsection{Country level variables}

Data for EF are sourced from the Global Footprint Network (see online appendix table A1). A reduced ecological footprint represents greater sustainability. We therefore enter

\footnotetext{
${ }^{13}$ To mitigate some inconsistencies across waves in the categorization of personal income, we include income solely as an ordinal variable.
} 
the negative value of EF into our regressions, denoted (EF), so that an increase in the resulting variable represents a greater level of sustainability.

Data for ANS and its components are sourced from the World Bank's World Development Indicators Database (WDI). ${ }^{14}$ We aggregate the ANS sub-categories into three components (each expressed as a percentage of GNI): net national savings (NNS, which equals gross national savings less consumption of fixed capital), education, and (natural capital depletion), where the parentheses for natural capital depletion again indicates that we take the negative value of this component so that an increase in the resulting variable represents greater sustainability.

For reasons highlighted earlier, we place little emphasis on the net national savings variable since the gross savings component of that variable is calculated as a residual (i.e., income less consumption expenditures and net transfers) and so incorporates inaccuracies arising from multiple components of the national accounts. In a case where a revision to just one component of the national accounts occurs without compensating adjustments elsewhere (as occurred in Nigeria in 2013), the gross (and net) national savings figure can change markedly. The same problem affects ANS which simply adds gross national savings to the other components. Consequently, the two components of ANS that relate to education and natural capital depletion are likely to be more accurate indicators of sustainability within a country than are ANS or NNS.

Other country level control variables, i.e., life expectancy and unemployment rate, ${ }^{15}$ were also sourced from the WDI database. The countries in our sample are mostly low to middle income countries as at 1990, with Spain having the highest GNI per capita at the start of the sample. While inclusion of the life expectancy variable helps to control for the stage of economic development of a country, the selection of countries should be borne in mind when interpreting the results. The data for EF, ANS and its components, mean SWB and the macro controls is provided in online appendix table A2.

\section{Results and discussion}

We initially estimate equation (2) using OLS for each of the two decades for five measures of sustainability: (i) (EF); (ii) ANS; (iii) NNS; (iv) education; and (v) (natural capital depletion). All variables other than dummy variables are standardised so that the coefficient represents the effect of a one-standard-deviation change in the explanatory variable on individual SWB. Rather than presenting all ten regressions in full, table 3 presents the relevant coefficients, with standard errors clustered by country, for each sustainability variable for each decade. Each cell represents the results of a separate equation.

Prior to discussing the sustainability estimates, we discuss results for the control variables. Online appendix table A3 presents the full equations for the two (EF) OLS equations including the estimates of the personal and macro control variables. (The estimates for these variables remain similar across all regressions so are not included in full for other specifications.) The results for the personal control variables are consistent with those of previous studies. For instance, SWB exhibits the standard U-shaped relationship with age (Gross et al., 1997). Prior studies show mixed results for the SWB of women relative to men (Schyns, 2002). In our estimates, women have positive relative SWB in the first decade but not the second. The results indicate that married people are

\footnotetext{
${ }^{14}$ Argentina does not have an ANS estimate for 1990; we use the ANS value from 1991 instead.

${ }^{15}$ Unemployment data series start from 1991 for all countries in the WDI data. We use 1991 values in each case.
} 
Table 3. OLS regressions. Dependent variable: SWB

\begin{tabular}{lcc}
\hline Sustainability variable & $1^{\text {st }}$ decade & $2^{\text {nd }}$ decade \\
\hline (Ecological footprint) & $-1.643^{\star \star \star}$ & 0.434 \\
& $(0.373)$ & $(0.405)$ \\
\hline ANS & -0.0945 & $-0.332^{\star \star \star}$ \\
& $(0.153)$ & $(0.0927)$ \\
\hline Net national savings & -0.0352 & $-0.246^{\star \star \star}$ \\
& $(0.139)$ & $(0.0590)$ \\
\hline Education & 0.0192 & 0.294 \\
& $(0.312)$ & $(0.261)$ \\
\hline (Natural capital depletion) & -0.417 & $0.462^{\star \star}$ \\
\end{tabular}

Notes: Ecological footprint and natural capital depletion are entered as sustainability variables, so are multiplied by -1 (indicated by parentheses). All coefficients are standardised. All equations include personal and macroeconomic controls. Standard errors (in parentheses) are clustered by country for all estimates.

${ }^{\star *} p<0.05 ;{ }^{* * *} p<0.01$.

happier than people of any other marital status, while significant SWB differences occur between occupational groups. Higher levels of both income and education are significantly and positively related to SWB consistent with prior studies. The consistency of our results for the effects of personal characteristics with prior literature provides confidence that our methods and data are suitable for the central foci of the paper. Three of the four macro control variables are also significant across the two decades, indicating that they help to control for country-specific factors.

A key feature of the results in table A3 (online appendix) is that prior country average SWB $\left(\mathrm{SWB}_{c, t 0}\right)$ is positively and significantly associated with higher life satisfaction of individuals in the subsequent period for each decade. The significance of this variable shows the criticality of controlling for prior SWB in any study of the relationship of current SWB with another lagged variable of interest.

The OLS results in table 3 indicate that a country that has a higher level of strong sustainability according to EF experiences lower wellbeing for its citizens over the next decade (after controlling for the country's initial SWB, macro position and personal characteristics). This result is significant at the 1 per cent level. Similarly, there is a negative (albeit not statistically significant) association of future wellbeing with a greater level of strong sustainability according to natural capital depletion over the initial decade.

In the second decade, this relationship reverses. Countries that exhibit a higher degree of strong sustainability experience higher SWB over the second decade (significantly so, according to the natural capital depletion estimate). The education component of ANS also exhibits a positive (albeit insignificant) association with wellbeing over the second decade but not the first. Each of these results is consistent with the hypothesis that conserving resources contributes to higher future wellbeing of residents.

In contrast to these results, we find no relationship between wellbeing and ANS or NNS over the first decade, while there is a negative relationship over the second decade. However the noise in the gross national savings data (which feeds into both NNS and ANS) makes it difficult to interpret these results further.

Table 4 presents the corresponding ordered logit results which produce almost identical findings to those in table 3 . Given the similarity in results, we conduct the remaining analysis using OLS. 
Table 4. Ordered logit regressions. Dependent variable: SWB

\begin{tabular}{lcc}
\hline Sustainability variable & $1^{\text {st }}$ decade & $2^{\text {nd }}$ decade \\
\hline (Ecological footprint) & $-1.162^{\star \star \star}$ & 0.364 \\
& $(0.308)$ & $(0.397)$ \\
\hline ANS & -0.0794 & $-0.333^{\star \star \star}$ \\
& $(0.125)$ & $(0.0900)$ \\
\hline Net national savings & -0.0323 & $-0.252^{\star \star \star}$ \\
& $(0.113)$ & $(0.0554)$ \\
\hline Education & -0.0198 & 0.359 \\
& $(0.252)$ & $(0.281)$ \\
\hline (Natural capital depletion) & -0.313 & $0.468^{\star \star \star}$ \\
& $(0.360)$ & $(0.169)$ \\
\hline
\end{tabular}

Notes: Ecological footprint and natural capital depletion are entered as sustainability variables, so are multiplied by -1 (indicated by parentheses). All coefficients are standardised. All equations include personal and macroeconomic controls. Standard errors (in parentheses) are clustered by country for all estimates.

${ }^{\star \star \star} p<0.01$.

Table 5. Tests of perfect substitutability within ANS (OLS regressions. Dependent variable: SWB)

\begin{tabular}{lcc}
\hline Sustainability variable & $1^{\text {st }}$ decade & $2^{\text {nd }}$ decade \\
\hline ANS & 0.0119 & $-0.0529^{\star \star \star}$ \\
& $(0.0158)$ & $(0.0100)$ \\
\hline (Natural capital depletion) & $-0.7024^{\star \star}$ & $0.8087^{\star \star}$ \\
Net national savings+Education & $(0.2908)$ & $(0.2703)$ \\
\hline
\end{tabular}

Notes: Natural capital depletion is entered as a sustainability variable, so is multiplied by -1 (indicated by parentheses). Variables are not standardised. All equations include personal and macroeconomic controls. Standard errors (in parentheses) are clustered by country for all estimates.

${ }^{\star *} p<0.05 ;{ }^{* \star *} p<0.01$.

Weak sustainability relies on the assumption that each form of capital is a perfect substitute for each other form of capital. For instance, if we had two subsets of capital, then weak sustainability implies linear indifference curves whereas strong sustainability implies convex indifference curves. In order to examine the validity of the weak sustainability approach, we estimate our previous specification for ANS with the addition of an extra variable, being the ratio of (natural capital depletion) to the sum of the other two components of ANS, i.e., net national savings plus education. If these other components are perfect substitutes for natural capital, then this ratio should not affect wellbeing outcomes once ANS is included in the specification. Table 5 presents the estimates for each decade for ANS and for the ratio variable (using non-standardised variables since we are testing whether the ratio of the raw variables matters). The results for ANS in table 5 are consistent with those in table 3.

Turning to the ratio variable, we see that the ratio is significant for each decade, implying that perfect substitutability between natural capital and other forms of capital does not hold. Reflecting the results in tables 3 and 4, the coefficient on the ratio variable indicates that over the first decade wellbeing is enhanced if, for a given level of ANS, the savings come through a switch out of natural capital into other forms of savings. By contrast, for the second decade, wellbeing is enhanced if the savings come through reduced natural capital depletion relative to other forms of saving. Thus, for an unchanged level of overall ANS but given the lack of perfect substitutability, we again see that natural 
Table 6. Testing demographic interactions (OLS regressions. Dependent variable: SWB)

\begin{tabular}{|c|c|c|}
\hline $\begin{array}{l}\text { Sustainability variable } \\
\text { Interaction term }\end{array}$ & $1^{\text {st }}$ decade & $2^{\text {nd }}$ decade \\
\hline \multicolumn{3}{|l|}{ (Ecological footprint) } \\
\hline Age & & $\star \star$ \\
\hline \multicolumn{3}{|l|}{ Sex } \\
\hline \multicolumn{3}{|l|}{ Education } \\
\hline \multicolumn{3}{|l|}{ Income } \\
\hline \multicolumn{3}{|l|}{ ANS } \\
\hline \multicolumn{3}{|l|}{ Age } \\
\hline \multicolumn{3}{|l|}{ Sex } \\
\hline Education & & $\star \star$ \\
\hline \multicolumn{3}{|l|}{ Income } \\
\hline \multicolumn{3}{|l|}{ Net National Savings } \\
\hline \multicolumn{3}{|l|}{ Age } \\
\hline \multicolumn{3}{|l|}{ Sex } \\
\hline Education & & $\star \star \star$ \\
\hline \multicolumn{3}{|l|}{ Income } \\
\hline \multicolumn{3}{|l|}{ Education } \\
\hline Age & & $\star \star$ \\
\hline \multicolumn{3}{|l|}{ Sex } \\
\hline Education & $\star \star \star$ & \\
\hline Income & $\star \star \star$ & \\
\hline \multicolumn{3}{|l|}{ (Natural Capital Depletion) } \\
\hline \multicolumn{3}{|l|}{ Age } \\
\hline \multicolumn{3}{|l|}{ Sex } \\
\hline Education & * & * \\
\hline Income & & * \\
\hline
\end{tabular}

Notes: All equations include personal and macroeconomic controls. Standard errors are clustered by country. Asterisks show where a binary interaction coefficient (age, sex, education or income) is significant for the association of a sustainability indicator with SWB. ${ }^{*} p<0.1 ;{ }^{\star \star} p<0.05 ;{ }^{\star \star \star} p<0.01$. Age interaction is $\geqslant 40$ years $(=1)$ versus $<40$ years $(=0)$; sex interaction is female $(=1)$ versus male $(=0)$; education interaction is primary or below $(=1)$ versus secondary or above $(=0)$; income interaction is decile $1-5(=1)$ versus decile $6-10(=0)$.

capital depletion is favourable for short-term wellbeing outcomes but is unfavourable for longer-term outcomes.

Additionally, we test the null hypothesis that the relationship between each of the sustainability indicators and wellbeing is identical for different population segments. We do so since some groups may fare better than others from greater education expenditure or from greater exploitation of natural capital. In order to conduct this test, we split our sample along four separate dimensions: age (less than 40 years / at least 40 years), sex (female / male), education (primary or below / secondary or above), and income (deciles 1-5/deciles 6-10). For each of these dimensions we interact a dummy variable 
for the relevant split with the sustainability measure that enters the equation. Table 6 summarises the results, indicating where the interaction term is significant (at the 10 per cent level or lower); blank cells indicate no significant interaction.

Five of the nine significant interactions relate to education. In examining the resulting coefficients, we find that more educated people (at the end of a decade) benefit more than the less educated from greater initial education expenditure. However, the high education group benefits less from a more sustainable natural capital depletion path, suggesting that more highly educated people may leverage a rundown in natural capital for their own benefit. This is especially evident over the second decade where the standardised coefficient on (natural capital depletion) for the less educated, at 0.665 , is almost twice that for the more educated. ${ }^{16}$ Similarly, high income people benefit more from education expenditures than do lower income groups but benefit less from running a more sustainable natural capital position over the second decade. To the extent that high income and highly educated people have greater political influence than others, these results imply that those in power may tend to favour greater education expenditures and may be less willing to prioritise conservation of natural capital.

\section{Conclusions}

We have addressed the question of whether there is a trade-off between adopting policies that promote near-term wellbeing and policies that promote sustainability. We test for this trade-off using measures of both strong and weak sustainability. We find that there is a short-run (decadal) trade-off between wellbeing and strong sustainability. In the subsequent decade, wellbeing bounces back for countries that exhibit a higher initial level of strong sustainability. Less educated people benefit more from running a strongly sustainable position, implying that natural capital depletion tends to benefit those with greater education relative to those with lower educational achievement. By contrast, more educated people benefit more from prior increases in education expenditures.

From a methodological perspective, our analysis raises doubts about the validity of aggregating different forms of capital together to form a single economically-meaningful capital measure such as ANS. Our results reject the hypothesis that natural capital is a perfect substitute for other forms of capital in both the short and the long run. Thus while ANS may have accounting validity (being the change in the sum of multiple capital components), it falls short as an economic sustainability measure.

A further test of substitutability that could be explored in future work is whether all aspects of natural capital (natural resource depletion, carbon dioxide emissions, and particulate matter emissions) are perfect substitutes and/or whether they have different wellbeing effects over different time horizons. For instance, particulate matter emissions may have immediate negative wellbeing impacts (Welsch, 2002) but have fewer longterm impacts, natural resource depletion may have greater long-term negative effects on wellbeing, while carbon dioxide emissions may have global but not local negative impacts. If these aspects are not perfect substitutes, then an aggregate measure even of strong sustainability may not be appropriate.

Methodologically, we also highlight the importance of controlling for prior wellbeing within a country when estimating effects of prior sustainability on current wellbeing. In our estimates, prior SWB is a highly significant explanatory variable, implying that

\footnotetext{
${ }^{16}$ All split coefficient values relating to the significant interaction terms are presented in online appendix table A4.
} 
studies that omit any control for prior wellbeing, as is the case with several previous 'levels-levels' studies (see table 1), are likely to be misspecified.

Our results are important for understanding political economy dynamics in relation to sustainability and wellbeing. A country that depletes its natural capital stocks may raise individuals' life satisfaction in the short term but diminishes the resources available to raise people's wellbeing over longer time horizons. We therefore highlight an important political economy challenge for policies designed to boost sustainable outcomes. Governments that promote a strong sustainability position for their country may suffer in the short term (i.e., the term most relevant to political cycles) and so potentially lose political power. This political economy challenge may help explain why many governments do not run sustainable policies even if this is at the expense of future generations' welfare. It may also explain why governments that do run sustainable policies may not last in power. Future research could concentrate on identifying generalisable lessons from specific countries that have been able to achieve both greater sustainability (strong and/or weak) and greater short-term wellbeing. The ability to cut through this Gordian knot is a challenge facing many governments that have the wellbeing of both current and future generations in mind.

Supplementary material. The supplementary material for this article can be found at https://doi.org/10. 1017/S1355770X20000509.

Acknowledgements. This research was funded through Royal Society of New Zealand Marsden Fund grant MEP1201. We thank the Associate Editor and three referees of this journal for valuable comments on an earlier version of this paper. We also thank Professor Les Oxley for his support through all stages of this project, and Shine $\mathrm{Wu}$ for his excellent technical assistance.

\section{References}

Arrow K, Dasgupta P, Goulder L, Mumford K and Oleson K (2012) Sustainability and the measurement of wealth. Environment and Development Economics 17, 317-353.

Bellemare M, Masaki T and Pepinsky T (2017) Lagged explanatory variables and the estimation of causal effect. The Journal of Politics 79, 949-963.

Blum M, McLaughlin E and Hanley N (2013) Genuine savings and future wellbeing in Germany, 1850-2000. Stirling Economics Discussion Paper, 2013-13. University of Stirling.

Blum M, Ducoing C and McLaughin E (2017) A sustainable century: genuine savings in developing and developed countries, 1900-2000. In Hamilton K and Hepburn C (eds), National Wealth: What Is Missing, Why It Matters. Oxford: Oxford University Press, pp. 89-113.

Bonini A (2008) Cross-national variation in individual life satisfaction: effects of national wealth, human development, and environmental conditions. Social Indicators Research 87, 223-236.

Bryan M and Jenkins S (2016) Multilevel modelling of country effects: a cautionary tale. European Sociological Review 32, 3-22.

Cantril H (1965) The Pattern of Human Concerns. New Brunswick, NJ: Rutgers University Press.

Cummins R (2012) The determinants of happiness. International Journal of Happiness and Development $\mathbf{1}$, $86-101$.

Dasgupta P (2020) The Dasgupta Review - Independent Review on the Economics of Biodiversity Interim Report. London: HM Treasury.

Dasgupta P and Heal G (1974) The optimal depletion of exhaustible resources. The Review of Economic Studies 41, 3-28.

Dasgupta P and Mäler K-G (2000) Net national product, wealth, and social wellbeing. Environment and Development Economics 5, 69-93.

Delhey J and Kroll C (2013) A "happiness test" for the new measures of national well-being: how much better than GDP are they? In Brockmann H and Delhey J (eds), Human Happiness and the Pursuit of Maximization. Netherlands: Springer, pp. 191-210. 
Diener E, Eunook M, Lucas R and Smith H (1999) Subjective wellbeing: three decades of progress. Psychological Bulletin 125, 276-302.

Diener E, Ng W, Harter J and Arora R (2010) Wealth and happiness across the world: material prosperity predicts life evaluation, whereas psychosocial prosperity predicts positive feeling. Journal of Personality and Social Psychology 99, 52-61.

Dietz S and Neumayer E (2007) Weak and strong sustainability in the SEEA: concepts and measurement. Ecological Economics 61, 617-626.

Di Tella R, MacCulloch R and Oswald A (2001) Preferences over inflation and unemployment: evidence from surveys of happiness. American Economic Review 91, 335-341.

Dodds S (1997) Towards a "science of sustainability": improving the way ecological economics understands human wellbeing. Ecological Economics 23, 95-111.

Engelbrecht H-J (2009) Natural capital, subjective wellbeing, and the new welfare economics of sustainability: come evidence from cross-country regressions. Ecological Economics 69, 380-388.

Engelbrecht H-J (2012) Some empirics of the bivariate relationship between average subjective wellbeing and the sustainable wealth of nations. Applied Economics 44, 537-554.

Ferreira S and Vincent J (2005) Genuine savings: leading indicator of sustainable development? Economic Development and Cultural Change 53, 737-754.

Ferreira S, Hamilton K and Vincent J (2008) Comprehensive wealth and future consumption: accounting for population growth. World Bank Economic Review 22, 233-248.

Ferrer-i-Carbonell A and Frijters P (2004) How important is methodology for the estimates of the determinants of happiness? The Economic Journal 114, 641-659.

Frey B and Stutzer A (2002) What can economists learn from happiness research? Journal of Economic Literature 40, 402-435.

Georgescu-Roegen N (1971) The Entropy Law and the Economic Process. Cambridge, MA: Harvard University Press.

Gnègnè Y (2009) Adjusted net saving and welfare change. Ecological Economics 68, 1127-1139.

Greasley D and Madsen JB (2017) The rise and fall of exceptional Australian incomes since 1800. Australian Economic History Review 57, 264-290.

Greasley D, Hanley N, Kunnas J, McLaughlin E, Oxley L and Warde P (2014) Testing genuine savings as a forward-looking indicator of future wellbeing over the (very) long-run. Journal of Environmental Economics and Management 67, 171-188.

Greasley D, Hanley N, McLaughlin E and Oxley L (2017) Australia: a land of missed opportunities? Environment and Development Economics 22, 674-698.

Grimes A and Hyland S (2020) Measuring cross-country material wellbeing and inequality using consumer durables. Scottish Journal of Political Economy 67, 248-271.

Grimes A, Ormsby J, Robinson A and Wong SY (2016) Subjective wellbeing impacts of national and subnational fiscal policies. REGION 3, 43-69.

Gross J, Carstensen L, Pasupathi M, Tsai J, GÓğtestam S and Hsu A (1997) Emotion and aging: experience, expression, and control. Psychology and Aging 12, 590-599.

Hamilton K and Atkinson G (2006) Wealth, Welfare and Sustainability: Advances n Measuring Sustainable Development. Cheltenham, UK: Edward Elgar Publishing.

Hamilton K and Clemens M (1999) Genuine savings rates in developing countries. World Bank Economic Review 13, 333-356.

Hanley N, Dupuy L and McLaughlin E (2015) Genuine savings and sustainability. Journal of Economic Surveys 29, 779-806.

Hanley N, Oxley L, Greasley D and Blum M (2016) Empirical testing of genuine savings as an indicator of weak sustainability: a three-country analysis of long-run trends. Environmental and Resource Economics 63, 313-338.

Hartwick J (1977) Intergenerational equity and the investing of rents from exhaustible resources. American Economic Review 67, 972-974.

Hartwick J (1990) Natural resources, national accounting and economic depreciation. Journal of Public Economics 43, 291-304.

Heine S, Lehman D, Markus H and Kitayama S (1999) Is there a universal need for positive self-regard? Psychological Review 106, 766. 
Helliwell J (2003) How's life? Combining individual and national variables to explain subjective wellbeing. Economic Modelling 20, 331-360.

Helliwell J and Putnam R (2004) The social context of well-being. Philosophical Transactions of the Royal Society of London. Series B 359, 1435-1446.

Helliwell J, Layard R and Sachs J (2012) World Happiness Report. New York: Columbia University.

Hicks J (1946) Value and Capital: An Inquiry Into Some Fundamental Principles of Economic Theory. Oxford: Clarendon Press.

Kahneman D and Krueger A (2006) Developments in the measurement of subjective well-being. Journal of Economic Perspectives 20, 3-24.

Leigh A and Wolfers J (2006) Happiness and the human development index: australia is not a paradox. Australian Economic Review 39, 176-184.

Luttmer E (2005) Neighbors as negatives: relative earnings and wellbeing. The Quarterly Journal of Economics 120, 963-1002.

MacKerron G (2012) Happiness economics from 35000 feet. Journal of Economic Surveys 26, 705-735.

McGregor J, McKay A and Velazco J (2007) Needs and resources in the investigation of well-being in developing countries: illustrative evidence from Bangladesh and Peru. Journal of Economic Methodology 14, 107-131.

Novak M and Pahor M (2017) Using a multilevel modelling approach to explain the influence of economic development on the subjective wellbeing of individuals. Economic Research-Ekonomska Istraživanja 30, 705-720.

OECD (2011) How's Life? Measuring Wellbeing. Paris: OECD Publishing.

Pearce D and Atkinson G (1993) Capital theory and the measurement of sustainable development: an indicator of weak sustainability. Ecological Economics 8, 103-108.

Pearce D, Hamilton K and Atkinson G (1996) Measuring sustainable development: progress on indicators. Environment and Development Economics 1, 85-101.

Pittau M, Zelli R and Gelman A (2010) Economic disparities and life satisfaction in European regions. Social Indicators Research 96, 339-361.

Polgreen L and Simpson N (2011) Happiness and international migration. Journal of Happiness Studies 12, 819-840.

Preston S (1975) The changing relation between mortality and level of economic development. Population Studies 29, 231-248.

Qasim M (2017) Sustainability and wellbeing: a scientometric and bibliometric review of the literature. Journal of Economic Surveys 31, 1035-1061.

Qasim M, Oxley L and McLaughlin E (2020) Genuine savings as a test of New Zealand weak sustainability. Environment, Development and Sustainability 22, 89-127.

Reed R (2015) On the practice of lagging variables to avoid simultaneity. Oxford Bulletin of Economics and Statistics 77, 897-905.

Schyns P (2002) Wealth of nations, individual income and life satisfaction in 42 countries: a multilevel approach. Social Indicators Research 60, 5-40.

Sen A (1999) Development as Freedom. Oxford: Oxford University Press.

Sneddon C, Howarth R and Norgaard R (2006) Sustainable development in a post-Brundtland world. Ecological Economics 57, 253-268.

Solow R (1974) The economics of resources or the resources of economics. American Economic Review 64, $1-14$.

Stiglitz J, Sen A and Fitoussi J-P (2010) Report by the Commission on the Measurement of Economic Performance and Social Progress. Paris: Commission on the Measurement of Economic Performance and Social Progress.

United Nations Economic Commission for Africa (2014) Nigeria's new GDP a sign of progress in shaping Africa's narrative - says ECA's Lopes. Available at https://www.uneca.org/stories/ nigerias-new-gdp-sign-progress-shaping-africas-narrative-says-ecas-lopes.

Veenhoven R (2007) Measures of gross national happiness. In OECD (ed.), Measuring and Fostering the Progress of Societies. Paris: OECD Publishing, pp. 232-253.

Vemuri A and Costanza R (2006) The role of human, social, built, and natural capital in explaining life satisfaction at the country level: toward a National Wellbeing Index (NWI). Ecological Economics 58, 119-133. 
Verme P (2011) Life satisfaction and income inequality. Review of Income and Wealth 57, 111-127.

Welsch H (2002) Preferences over prosperity and pollution: environmental valuation based on happiness surveys. Kyklos 55, 473-494.

Welsch H and Kühling J (2016) How has the crisis of 2008-09 affected subjective wellbeing? Evidence from 25 OECD countries. Bulletin of Economic Research 68, 34-54.

Cite this article: Qasim M, Grimes A (2021). Sustainability and wellbeing: the dynamic relationship between subjective wellbeing and sustainability indicators. Environment and Development Economics 1-19. https:// doi.org/10.1017/S1355770X20000509 